\title{
Fichte and Kant on Reason's Final Ends and Highest Ideas
}

Steven Hoeltzel

\section{(2) OpenEdition \\ Journals}

Electronic version

URL: http://journals.openedition.org/ref/827

DOI: $10.4000 /$ ref.827

ISSN: 2258-014X

Publisher

EuroPhilosophie Editions

\section{Electronic reference}

Steven Hoeltzel, «Fichte and Kant on Reason's Final Ends and Highest Ideas », Revista de Estud(i)os sobre Fichte [Online], 16 | 2018, Online since 01 December 2018, connection on 08 September 2020. URL : http://journals.openedition.org/ref/827 ; DOI : https://doi.org/10.4000/ref.827

This text was automatically generated on 8 September 2020

(c) EuroPhilosophie 


\title{
Fichte and Kant on Reason's Final Ends and Highest Ideas
}

\author{
Steven Hoeltzel
}

The Wissenschaftslehre, Fichte states in the 1797 Second Introduction, is a philosophy that "is in complete accord with Kant's and is nothing other than the Kantian philosophy properly understood" (IWL, 52; GA I/4, 221). Later in the same essay, he singles out, as a focal point of his own position, "the I as an Idea" (IWL, 100; GA I/4, 265). Not to be confused with the I "as an intellectual intuition," with which the Wissenschaftslehre is said to commence (ibid.), this Idea of the I, in which the system is said to culminate, indicates the essence of reason or of the rational being qua rational: "Das Ich, als Idee, ist das VernunftWesen" (GA I/4, 266). On Kant's account, of course, reason's most basic aims and operations engender not one but three systematically central Ideas, each of which represents an entity that transcends any possible experience, and all of which play a privileged (but not always unproblematic) role in orienting properly rational cognition and volition. These are the Ideas of the soul, the world-whole, and God - and the Fichtean Idea of the I, despite its purportedly pure-rational pedigree and avowedly regulative role, is not in any obvious way a member of that Kantian triad. So the question arises: Concerning the nature of pure reason and the content and status of its supreme self-wrought Idea, what exactly is Fichte's position, and how might it represent "the Kantian philosophy properly understood"? The issue is by no means merely scholastic, for it is only in Kant's rendering of reason (not of the understanding or of sensibility) that his transcendental model of mentality provides a foundation for self-appointed approximation to pure, non-arbitrarily self-legislated optima, and thus for proactive autonomy of a properly rational kind. Clearly these are major themes for Fichte also, but it is much less clear whether his treatment of them is Kantian in anything more than its basic inspiration.

2 Below I argue that Fichte's account of pure reason and its supreme self-wrought Idea is, in its transcendental essentials, very much modeled on Kant's. The key difference between their positions, I suggest, is simply that Fichte operates with a more abstract understanding of the transcendentally basic elements of finite rationality; 
consequently, he arrives at a conceptually more concentrated understanding of pure reason's preeminent Idea. In section one, I supply some context for that comparison. In section two, I recount Fichte's depiction of "the I as an Idea" and note some importantly related concepts and claims. In section three, I examine a pair of interestingly different approaches taken by Kant to understanding and identifying the Ideas engendered by reason's basic aims and operations. Finally, in section four, I suggest that the Jena Wissenschaftslehre reflects Fichte's tacit appropriation of the transcendentally more fundamental of those two Kantian approaches.

\section{Preliminaries}

3 In Kant's writings the term "reason" has both a generic and a more specialized sense. Generically, reason is a capacity to originate and instate pure, non-arbitrary ordering forms (cf. A11/B24). Such forms, however, are of more than one sort and function in more than one way. The pure concepts of the understanding, aka the categories, informationally enrich and comprehendingly combine the given elements comprised by any possible cognition (B143), including any cognition whereby discrete, putatively mind-independent objects are apprehended (B160-1). An object, on this account, is "that in the concept of which the manifold of a given intuition is united" (B137), and the categories are the basic forms of synthesis upon which all such unification depends. Consequently, "all synthesis, through which even perception itself becomes possible, stands under the categories, and since experience is cognition through connected perceptions, the categories are conditions of the possibility of experience, and are thus also valid a priori of all objects of experience" (B161).

4 By contrast, reason, in the specialized sense of "reason" that distinguishes this faculty from the understanding, works in another way and at a higher level. The source of unwavering, recognizably rational demands - the demand, for example, that things be completely explained and the world optimally comprehended (A644-5/B672-3) reason also authors Ideas of transcendent entities that would have to exist, were reality so configured as to allow for the complete satisfaction of reason's self-wrought requirements. Unlike the categories of the understanding, these Ideas of reason are not constitutive of objects that we can experientially apprehend or verifiably cognize (ibid.). Nevertheless, these Ideas play an indispensable regulative role, orienting the use of the understanding by guiding us in our approximation to optima that reason upholds a priori (A672/B700).

Thus, while both the understanding and reason exhibit intellectual spontaneity, only reason's operations provide for the more complex kind of intellectual autonomy: the power of intelligence to independently author and authorize ends and, in so doing, to determine itself to deploy its powers for the sake of those ends. To be sure, there is a distinct but epistemologically significant sense in which the understanding is autonomous: it functions as a law unto itself in articulating a priori the basic categorial structure of empirically cognizable nature (B163-5). Nevertheless, the basic operations that make that possible (viz., syntheses) do not themselves comprise the setting of ends, and the nonsensory notions deployed in those operations (viz., categories) are descriptive concepts void of prescriptive import. Accordingly, autonomy, understood as fully-fledged and strictly rational self-determination, must be rooted in activities of reason, as opposed to operations of the understanding. (Notably, Kant himself does not 
introduce the term "autonomy" until 1785 , in the Groundwork, where it principally concerns the determination of the will by reason's self-wrought law.)

Understanding "reason" and "autonomy" in the senses just supplied, I would argue that the autonomy of reason plays a transcendentally more radical role, and thus receives a transcendentally more radical vindication, in the Jena Wissenschaftslehre than in Kant's Critiques. By "more radical" here, I mean "concerning a more basic kind of cognitive accomplishment" - so that, for example, a transcendental argument premised upon the possibility of truth-apt, object-directed, first-order cognition would be more radical than one premised upon a higher-order propensity to further organize and elaborate upon first-order cognitions in some specified way. In Kant's theoretical philosophy, the autonomy of reason is invoked in order to account for such higher-order propensities, as well as various ideas to which those propensities give rise. It is not, however, invoked as an enabling condition for empirical cognition per se, which (on Kant's account) requires only the categorial synthesis of passively registered appearances. In Fichte, by contrast, the autonomy of reason - specifically, the transcendental subject's authoring and approximating to a recognizably rational ultimate goal: absolutely unrestricted rational activity - is argued for as a necessary condition for the possibility of empirical cognition in the Kantian sense. This is the position summed up in Fichte's claim that "without a striving, no object at all is possible" (SK, 233; GA I/2, 399). In this way, the autonomy of reason is accorded a deeper transcendental foundation in Fichte's philosophy than in Kant's.

7 A detailed defense of that contention would be more than this essay can accommodate. Instead I shall support a related, more basic claim: that Fichte's understanding of reason, especially with respect to its final goal and its highest Idea, is substantially modeled on Kant's - in its transcendental deep-structure, of course, granted that the specifics of their surface-level articulations diverge.

\section{Fichte on the I as an Idea}

8 Fichte states in the Second Introduction that the transcendental subject whose activities the foundational portion of the Wissenschaftslehre isolates and explicates is a selfpositing subject to or for which "the I is present as an Idea" (IWL, 100; GA I/4, 266) - that is, not as the object of an intuition or the topic of some discrete cognition, but instead as "the ultimate aim of reason's striving" (IWL, 101; GA I/4, 266): the end or optimum with and toward which the rational subject, qua rational, orients itself. At no point is either the transcendental subject (the I) or the transcendental philosopher (Fichte) under any illusion that the indicated ideal is or even could be actual. "It will never become anything real," Fichte says. "Instead, it is only something to which we ought to draw infinitely nearer" (ibid.). Although we can never completely coincide with this ideal, we can always incrementally advance toward it, and pure reason prescribes unceasing endeavor to that end: "The final end of a rational being necessarily lies in infinity; it is certainly not an end that can ever be achieved, but it is one to which a rational being, in consequence of its spiritual [geistigen] nature, is supposed to draw ceaselessly nearer and nearer" (SE, 142; GA I/5, 141).

But what is the content of this irrevocable albeit unreachable ideal? The I as an Idea, Fichte says, is "das VernunftWesen" (GA I/4, 266). This locution might be rendered as "the essence of reason" or as "the rational being," and both notions seem to be blended 
here: the I as an Idea is das Vernunftwesen "insofar as this being has completely succeeded in exhibiting universal reason within itself, has actually become rational through and through, and is nothing but rational. As such, it has ceased to be an individual, which it was only because of the limitations of sensibility" (IWL, 100; GA I/4, 266). What is essential to rational activity, on Fichte's account, is the self-initiated and self-transparent origination and instatement of pure ordering forms, chief among them a self-wrought but essentially impersonal highest goal: "the self-sufficiency of all reason as such" (SE, 220; GA I/5, 209). Relative to such pure-rational purposiveness, the individual's own perspective, insofar as it is constituted by adventitious sensory and affective states, is inessential and unimportant. "It is for I-hood [Ichheit] as such a contingent fact that I, individual A, am precisely A" (ibid.). Thus, insofar as the I as an Idea "has actually become rational through and through," this being neither identifies with nor prioritizes any particular persona rooted in rationally-unbidden empirical givens. Our empirically qualified individuality, on Fichte's view, "is something merely accidental. Reason is the end and personality is the means; the latter is merely a particular expression of reason, one that must increasingly be absorbed into the universal form of the same" (IWL, 90; GA I/4, 257-8).

Still, the adoption of a purely impersonal outlook and ethic cannot be all that it takes to satisfy reason's constitutive commitment to its own absolute self-sufficiency.

The I as an Idea is the rational being insofar as this being has also succeeded in completely realizing reason outside of itself in the world, which thus also remains posited within this Idea. The world remains in this Idea as a world as such, i.e., the substrate along with these particular mechanical and organic laws; but these are here geared completely toward exhibiting the final goal of reason. (IWL, 100-1; GA $\mathrm{I} / 4,266)$

11 Such a rational being has not only outgrown its earlier identification with an empirically constricted personal perspective. It has also imposed rationally-mandated order upon all that is of arational origin, by systematically comprehending it and dutifully reconfiguring it. Thus, although this being still relates to a world outside of itself, it has so thoroughly (and, as it were, impersonally) grasped and reworked the latter that "reason and reason alone ... have dominion in the sensible world" (SE, 262; GA I/5, 246). For the I as an Idea, the "entire sensible world," not just the articulated individual body, subsists as the instrument and embodiment of pure reason's purposes (SE, 217; GA I/5, 208).

Note that Fichte sometimes depicts finite reason's final goal in an even more unqualified and rarefied way: as a mode of existence in which reason's self-wrought purposes are not at odds with the sensible world's "mechanical and organic laws" because pure reason's order-inducing activities are not confronted with and qualified by any sensible states of affairs whatsoever. In the Second Introduction, he states that the I as an Idea "can be exhibited only within the practical portion of philosophy, where it is shown to be the ultimate aim of reason's striving" (IWL, 101; GA I/4, 266). And in the practical portion of the 1794/95 Foundation of the Entire Wissenschaftslehre, he says that "the meaning of the principle, das Ich setzt sich selbst schlechthin, first becomes wholly clear" only with reference to an Idea of the "absolute I" or "infinite I" (absolute Ich; unendlichen Ich) in the light of which the I ought to "encompass all reality and exhaust

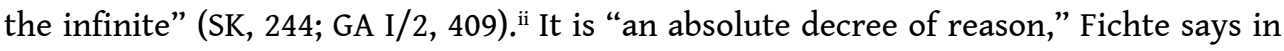
the same text, that "finitude itself must go; all bounds must fall away, and the infinite I must alone remain, as one and all" (SK, 137-8; GA I/2, 301). I take it that if "all bounds 
must fall away," then reason, as the self-initiated and self-transparent origination and instatement of pure ordering forms, must cease to find its own purity and spontaneity confronted and qualified by the opaque and unchosen givens that are constitutive of sensory or affective awareness and thus productive of finite reason's characteristic receptivity and reactivity.

Because such strong statements predate those quoted above from the 1797 Second Introduction, we might suppose that in the intervening time Fichte's conception of reason's final end was moderated or more adequately expressed. With respect to the above issue, however, this is not entirely clear. In the 1798 System of Ethics, for example, Fichte says that "the complete annihilation of the individual and the fusion of the latter into the absolutely pure form of reason or into God [in die absolut reine Vernunftform oder in Gott] is indeed the ultimate goal of finite reason" (SE, 143; GA I/5, 142). And his view at around this time is that God, unlike the I as an Idea, could not be subjectively situated over against a sensible world - not even as that world's omnicomprehender and indomitable orderer. Instead, what he calls "God" just is a supersensible world order (IWL, 151; GA I/5, 354), where the intended sense of "order" does not principally denote an already-accomplished arrangement (ordo ordinatus) but signifies, instead, an ongoing, originative, autonomous ordering (ordo ordinans: IWL, 160-1; GA I/6, 373-4). "God," understood as die absolut reine Vernunftform, must be rational activity - the selftransparent, self-initiated origination and instatement of ordering form - grounding what there is and doing so in the light of its own (purely rational) decree as to what there ought to be. Accordingly, this must be absolutely pure rational activity, not reactively mastering a rationally-unbidden mass of sensory and affective manifestations, but proactively unfolding into a self-wrought supersensible order: a universe of purposively evolving mental activity, not of nomologically constrained material conditions. .ii

On the one hand, then, we have the I as an Idea: the supreme knower and reformer of a sensible sphere with which rational being remains in relationship. (As noted above, "the world remains in this Idea as a world as such, i.e., the substrate along with these particular mechanical and organic laws..." (IWL, 100; GA I/4, 266).) And on the other hand, it seems, we have "the absolutely pure form of reason," unbeholden to empirical givens, autonomously articulating itself into a supersensible array of self-transparent, self-initiated activities. Moreover, it seems that any transition from I-as-idea to absolutely pure form would entail not only the aforementioned "annihilation of the individual," qua empirically-qualified personality, but also an end to experience as we know it: subjective confrontation by adventitious appearings must cease - and, with this, the sensible world must vanish - when "all bounds fall away" and only the absolutely pure form of reason remains. And on Fichte's view, as is well known, we "cannot think of personality and consciousness apart from limitation and finitude" (IWL, 152; GA I/5, 355).

Note, however, that this claim, properly understood, does not entail that the absolutely pure form of reason must be void of any inner or mental life. Granted, rational activity's total freedom from empirical entanglements would preclude the specific sort of consciousness that requires and arises out of pure activity's confrontation by adventitious manifestations: empirically circumscribed and perspectivally individualized consciousness. But even as he underscores precisely that point, Fichte also argues that "as regards content, divinity [Gottheit] is nothing but consciousness; it 
is intelligence, pure intelligence, spiritual life and activity" - albeit of a sort that eludes exact comprehension owing to its constitutive lack of limitations (AD, 178; GA I/6, 51). Note also his related, roughly contemporaneous rendering of "infinite reason" as an end-directed supersensible ordo ordinans (VM, 99; GA I/6, 284). Evidently, just as the Kantian categories, purified of their sensibly-schematized senses, can still articulate a range of thinkable supersensible structures (B304-5), so pure rational acts, free of entanglement with adventitious arational manifestations, could generate and sustain an ideally ordered, indefinitely complex array of extrasensory accomplishments. Of course, such considerations are not supposed to constitute epistemic grounds for affirming the actuality or attainability of the absolutely pure form of reason, thus understood. Instead, they concern only how we might best envision a certain rationally-mandated regulative ideal..$^{\text {iv }}$

But do we have just one regulative ideal here, or are there two? The preceding paragraphs stress some interesting differences between the I as an Idea and the absolutely pure form of reason, as Fichte sometimes depicts them. But then again, in the texts each of these is accorded what appears to be the same supreme standing, namely, that of the "ultimate aim of reason's striving" or "ultimate goal of finite reason." (I take the two expressions to be equivalent, because for Fichte, reason strives - in other words, autonomously undertakes to overcome impediments to its insight or efficacy - only because and insofar as it finds itself to be finite - that is, confronted by conditions not authored by its own activities.) Thus the question arises whether the above exegesis fabricates or exaggerates differences that Fichte himself would not acknowledge or emphasize. And there seem to be pertinent considerations pointing in both directions.

For one, the basic criteria in the light of which the two notions appear importantly distinct - roughly: (i) empirically conditioned, thus partly receptive and reactive, versus (ii) absolutely unconditioned, thus perfectly pure and proactive - are categories that play a fundamental organizing role in Fichte's philosophy, going all the way back to the innovations of the Aenesidemus review (EPW, 75; GA I/2, 65). Thus the separation suggested above, which distinguishes the I as an Idea from reason's absolutely pure form, reflects a distinction that has major philosophical significance for Fichte. However, there may be reasons for doubting the distinction's applicability in this instance. In the light of Fichte's epistemology, it is questionable whether anything like experience (as Fichte understands it) is possible relative to the subjective situation (if it can be called that) of the I as an Idea. And if the I as an Idea should prove to be insusceptible of experience, then it is unclear why we should not envision it as having already accomplished the striven-for "fusion ... into the absolutely pure form of reason or into God." In that case, "I as Idea" and "absolutely pure form of reason," while possibly differing in intension, would actually denote one and the same optimum.

To sketch the related reasoning: On Fichte's account of the essential inseparability of thinking and willing, the transcendental subject cannot find itself compelled to cognize an extra-subjective situation unless it finds its pure-rational aspiration to absolute selfsufficiency somehow contested or checked. But can the I as an Idea find itself thus frustrated? This may appear doubtful, insofar as Fichte states that such an I's selfsufficiency should involve "everything that I will to occur in my entire sensible world occurring purely and simply because I will for it to occur - just as happens in my body" (SE, 217; GA I/5, 208). This makes it unclear whether, and if so how, such an I would still 
be encumbered by "representations accompanied by the feeling of necessity" (IWL, 8; GA I/4, 186) - in which case it is unclear why or how the I as Idea should still have anything like experience, as Fichte conceives of the latter.

Nevertheless, I suggest that the I as an Idea is best understood to be subjectively situated in such a way as still to undergo experience of a sort. This I, it seems, still has a sensible world - underscore "sensible." In consequence, even though that world, at this ideal limit, is one in which no object or event can elude reason's comprehension or thwart reason's aim, still, the very sensory presence to consciousness of such a world must be understood, in the light of Fichte's epistemology, to betoken a persistent limitation of the I's free activity. This might very well be the very last such limitation, so to say, before that threshold (or "fusion") at which "all bounds must fall away, and the infinite I must alone remain, as one and all" (SK, 138; GA I/2, 301). Nonetheless, it remains a limitation, because for Fichte, any sensation of some putatively extrasubjective state of affairs goes back to some sheer "feeling" that is not posited through, and that remains recalcitrant in relation to, the I's self-initiated rational activities (cf. IWL, 75; GA I/4, 242-3). On Fichte's transcendental epistemology, it is just such recalcitrance which underpins and eventuates in experience.

20 I take it, then, that the I as Idea is the rational being that, having "succeeded in completely realizing reason outside of itself in the world" (IWL, 100; GA I/4, 266; my emphasis), nonetheless still finds itself subjectively situated over against an experienced objectivity, as distinct from the freely self-wrought and perfectly selftransparent ideal order that would be the expression of reason's absolutely pure form. Such a rational existence remains empirically conditioned - to the minimum conceivable degree, perhaps, but still sufficiently so to confine it to this side (our side) of the boundary beyond which lies reason's absolutely pure form alone. For Fichte, the absolute self-sufficiency for which the rational being finally strives requires "absolute indeterminability through anything outside" of rational being as such (SE, 61; GA I/5, 70). Accordingly, I take it that "I as an Idea" and "absolutely pure form of reason" stand for intimately related but ultimately distinct ideals.

21 Further considerations supporting such a reading issue straightforwardly from Fichte's first principles, insofar as the latter entail that "without a striving, no object at all is possible" (SK, 233; GA I/2, 399). On this account, the subject's countenancing of something other than its own states and acts - that is, the I's positing of the not-I presupposes and subserves a transcendentally prior end-directedness. Because the end in question is an end commitment to which precedes and prompts the I's positing of the not-I, that end cannot itself be - but nonetheless might entail, as a specification or subordinate goal - the complete conquest of the not-I by the I. Accordingly, purerational activity as such, the transcendentally most basic instance of which is the I's sheer positing of itself, must somehow contain or constitute commitment to an even more radical form of rational self-sufficiency, one that surpasses even such independence as would be achieved upon the completed conquest of the not-I by the I or via the rational mastery of the sensible world by the I as an Idea. And what could that more radical form of rational self-sufficiency consist in, other than pure-rational activity's permanent disengagement from all adventitious empirical manifestation? As Fichte phrases this in 1799, it is "the goal of our entire existence and all of our acting a goal that is indeed never to be reached but is to be unceasingly promoted - that rational being become absolutely and entirely free, self-sufficient, and independent of 
everything that is not itself reason" (AD, 101; GA I/5, 426; my emphasis). Viewed from this angle, it appears that finite rational being's inherent ultimate goal must be complete coincidence with the absolutely pure form of reason - an accomplishment of which even the I as an Idea, per the analysis above, falls short.

But where does all of this leave us? If the I as an Idea and the absolutely pure form of reason are best not conflated, how then are we to understand Fichte's apparent inclination to equate them by according supreme standing to each? And what has any of this got do to with Kant?

\section{Kantian routes to Ideas of reason}

The Kantian framework for identifying and interrelating pure reason's Ideas and ends suggests one way in which we might begin to clarify this picture. As I further explain below, in the Kantian context, an Idea of reason always derives from some basic end of reason, as a way of envisioning the satisfaction of some condition on said end's eventual realization. If we approach Fichte's position as this schema suggests, then we may say that for the Jena Wissenschaftslehre, (i) fusion into reason's absolutely pure form is the self-imposed final goal of finite rational activity as such, and (ii) the I as an Idea indicates the optimum of I-hood (Ichheit) attainable by the rational being qua finite: the penultimate (not ultimate) rational accomplishment short of the perfectly purified, absolutely unconditioned 'divinity' (Gottheit) of die absolut reine Vernunftform. If that is correct, then the I as an Idea serves as a kind of avatar for an ideal whose further independence from basic limitations locates it outside of the finite-rational frame of reference altogether. In that case, we can understand Fichte's tendency to identify reason's highest goal with now one and then the other as a result of context-driven decisions to take up different angles on the project proper to pure reason. One angle homes in on the highest goal of finite rational activity qua rational, as said goal is disclosed to higher-order transcendental reflection - namely, as complete coincidence with the absolutely pure form of reason. The other angle, which emphasizes the I as Idea, focuses instead on the first-order perspective of the finite rational being, for whom that goal makes itself manifest via a relatively indeterminate regulative representation of maximal rational self-sufficiency.

The question now is whether the above appeal to a Kantian prototype is supported by anything other than such schematic considerations. Why suppose that Fichte is consciously taking inspiration from Kant's approach? Why then does he not also discuss syllogistic form, transcendental illusion, and so forth? I address these questions below, but first, a disclaimer: My aim is not to offer any especially exact or comprehensive rendering of Kant's account of reason's ends and Ideas. ${ }^{v}$ Instead, my aim is merely to descry in his writings some key ideas and characteristic approaches that we might then see to be importantly implicated in Fichte's philosophy.

In the first Critique, Kant argues that the purest and most authoritative of reason's selfwrought Ideas (i) are three in number, (ii) are importantly affiliated with the three basic syllogistic forms undergirded by the three pure categories of relation, and (iii) tend to engender a type of "transcendental illusion" in which we mistake projected ideals for apprehended actualities. Obviously such claims have no clear echoes in the Jena Wissenschaftslehre. Still, we should consider how exactly Kant arrives at this 
position - and, in particular, how he proposes to identify and understand reason's key Ideas.

For Kant, "rational being is distinguished from the rest of nature by this, that it sets itself an end" (GMM 86, AK 4:437). vi With respect to "reason's speculative interest" specifically (A676/B704), the end in question is all-encompassing and ideally systematic comprehension, the achievement of which would satisfy the "need of reason" to "bring the highest possible unity of reason into our cognition" (A309/B365). To do so would require, among other things, that reason "find the unconditioned for conditioned cognitions of the understanding" (A307/B364), which discovery would (with respect to the relevant object-domain) effect the systematic closure that reason seeks in its quest for ever more-complete explanations - in particular, by uncovering something that (i) explains the facts for which further grounds are sought and, crucially, (ii) itself stands in no need of explanation, being absolutely basic, all-embracing, or independent in a way that obviates any further inquiry. No object of empirical cognition could ever possess that status, so the rational requirement to "find the unconditioned" refers us beyond the bounds of experience and invites us to envision some transcendent entity or entities that answer to that demand (A327/B384). Enter the Ideas of reason: pure notions, originated a priori, describing entities that transcend possible experience and that, relative to reason's essential ends, ought to exist, for the reason that their actual existence would be a necessary condition for the possible completion of a project that is integral to rationality as such.

But why "Ideas" in the plural? By what route does Kant arrive at distinct Ideas - not to mention insistent illusions - of God, the world-whole, and the soul, if his starting point is simply reason's aspiration to uncover the unconditioned? One answer, put as briefly as possible, is this: Reason demands ever more-complete explanations, and the logic of explanation is essentially syllogistic. Syllogisms come in three basic forms, underwritten by the three pure categories of relation (A323/B379). Accordingly, explanation comes in three different forms: explanation in terms of ontological inherence, in terms of lawful dependence, and in terms of systematic interconnection (ibid.). In consequence, the unconditioned that reason seeks takes three distinct shapes: "a subject that is no longer a predicate ... a presupposition that presupposes nothing further, and ... an aggregate of members of a division such that nothing further is required" (A323/B379-80). On this basis, Kant claims, we can see how

reason, exclusively through the synthetic use of the same function it employs in the categorical syllogism, must necessarily come to the concept of the absolute unity of the thinking subject, how the logical procedure in hypothetical syllogisms [leads to] the ideas of the absolutely unconditioned in a series of given conditions, and finally how the mere form of the disjunctive syllogism necessarily carries with it the highest rational concept of a being of all beings.... (A335-6/B392-3)

Moreover, Kant maintains, because these three Ideas are (on this model) so tightly enmeshed with the basic ways in which we make (properly rational) sense of things, it becomes difficult to resist the resulting, inexplicit intimation that we possess nonsensory surety of the indicated entities' actuality - especially insofar as we (precipitately) suppose that the world really does totally make sense: something that is indeed assumed, but by no means guaranteed, by reason's unceasing insistence that we work toward total understanding. Ergo "transcendental illusion," in which a priori projections reflecting reason's ideals (A674/B672) are misconstrued as non-sensory apprehensions of objective actualities (A297-8/B353-4). 
29 At this point it may seem as if Fichte's position has faded completely from view. However, the above considerations, although textually preponderant in the Critique, are not the only grounds, nor the most enduring ones, on the basis of which Kant identifies the purest and most authoritative of reason's self-wrought Ideas. He also has a separate and longer-lived line of argument, ${ }^{\text {vii }}$ still deployed in the Critique, which does not seek to graft those Ideas onto categorially-circumscribed syllogistic forms and which, because it bypasses that explanatory machinery, lends much less support to his later claims concerning the inevitability and tenacity of transcendental illusion. viii Below I propose that Fichte appropriates and adapts this approach, which, in Kant's application of it, derives the triplicity of reason's transcendental Ideas not from the three categories of relation, and so on, but from the threefold elementary articulation of reason's unchosen informational environment. Here is the Critique's version of this device:

Now what is universal in every relation that our representations can have is 1) the relation to the subject, 2) the relation to objects, and indeed either as appearances, or as objects of thinking in general.... Now all pure concepts have to do generally with the synthetic unity of representations, but concepts of pure reason (transcendental ideas) have to do with the unconditioned synthetic unity of all conditions in general. Consequently, all transcendental ideas will be brought under three classes, of which the first contains the absolute (unconditioned) unity of the thinking subject, the second the absolute unity of the series of conditions of appearance, the third the absolute unity of the condition of all objects of thought in general. (A3334/B390-1)

As noted above, theoretical reason has as its final goal perfected comprehension: it demands ideally complete explanation and aims to connect all well-founded cognitions within a system whose ideal articulation reflects reason's absolute imperative to effect optimal intelligibility. The design of this system and the accordant direction of our cognitive projects is reason's autonomous accomplishment. But the ensuing purerational project can actually unfold only within a given informational environment, and on the model outlined above, this environment has a threefold basic articulation that differentiates and relates (i) the experiencing subject, (ii) things considered as they are experienced by that subject, and (iii) things considered as they are in general. As a result, reason's essentially unitary project - that of systematically accounting for everything - is diffracted, as it were, into three lines of inquiry with distinct domains. And in consequence, reason projects three transcendental Ideas, representing transcendent entities each of which would have to exist, were everything in each domain to be optimally comprehensible. These are Ideas of the soul as a unitary enduring substance, of the sensible world as a unitary and comprehensively configured whole, and of a "being of all beings" as the one unconditioned source of all things in their systematic interconnection (A334/B391).

Below I propose that Fichte tacitly appropriates and adapts this diffraction model (as I will call it) in his own treatment of the ends and Ideas of pure reason. First, the better to prepare that comparison, we should also outline the relationship between reason's ends and Ideas in Kant's practical philosophy. Here, the end which, "given by reason alone, must hold equally for all rational beings" (GMM 78, AK 4:427), is the goal of optimized autonomy: the ideal arrangement or "highest good" in which (i) each individual autonomously commits to the autonomy of rational beings in general, and (ii) consequently all individuals succeed in self-actualization to the greatest extent possible consistent with the same for all others. ${ }^{i x}$ In us, however, commitment to this 
rationally self-legislated end is constantly contested by arational inclinations; thus, reason's intrinsic commitment to optimized autonomy manifests itself to the individual as an authoritative ethical directive, addressed to the inclination-prone will of a being enmeshed in and causally conditioned by an amoral natural order. Reason thereby places us under a demand that can be fully satisfied only if certain basic conditions obtain - namely (on Kant's view) only if one's will is essentially free and one's personality immortal, and only if there exists a guarantor (aka God) that the moral perfection of each would issue in the successful self-actualization of all. Consequently, in this connection also, pure reason upholds Ideas of the soul, the world-whole, and God - not in this case as projections orienting a theoretical quest for perfect comprehension, but instead as postulates underwriting an ethical project of optimal self-actualization. ${ }^{x}$ We can in principle obtain no evidence for (or against) the real being of the entities thus postulated, but we remain under an unconditional rational requirement to assent to their existence: the evidence is, necessarily, silent on that question, and reason as such categorically demands our complete commitment to a goal that is attainable only on the supposition that the indicated states of affairs obtain. Thus the Ideas that eventuate accordingly, while they do not add to our stock of warranted cognitions, still crucially contribute to reason's regulation of our conduct, by framing the basic outlook that sustains our essential vocation. Whether that vocation's final goal actually is attainable must remain unknown - but we cannot renounce it without renouncing reason itself, at least on Kant's (and Fichte's) conception of the latter as inherently oriented by requirements that derive from the highest of the ends that it sets for itself.

In the Kantian context, then - whether theoretical or practical - an Idea of reason is a nonsensory representation, elaborated a priori, of an entity that transcends possible experience and that, relative to pure reason's ultimate ends, ought to exist, in the sense that its actual existence would be a necessary condition for the eventual (not so say assured) completion of a project that is integral to reason as such. An Idea of reason is not itself, immediately, a representation of any final goal of reason, but its descriptive content and regulative function derive from and depend upon reason's constitutive commitment to some ultimate end. Reason's highest aim in the theoretical sphere is perfected comprehension, and in the practical sphere, optimized autonomy - but in each of these two contexts, reason's self-wrought supreme goal undergoes a kind of diffraction or differentiation at the interface with reason's unchosen environment, and Ideas of reason multiply accordingly.

\section{The Fichtean route to the I as an Idea}

I suggest that in thinking about pure reason's ends and the associated Ideas, Fichte tacitly takes over Kant's diffraction model - but with the important difference that (i) Fichte feeds into the model a more rarefied and unitary conception of reason's highest goal, and (ii) Fichte fits out the model with a more abstract understanding of the basic character of reason's unchosen environment. In consequence there eventuates, from the interface of reason's highest self-wrought goal with its unbidden empirical impediments, only a single supremely pure and authoritative Idea: the I as an Idea. ${ }^{\mathrm{xi}}$ Nevertheless, the model employed and the refinements applied by Fichte have solid foundations in Kant's earlier work. 

states in the nova methodo that Kant

speaks of an interest of speculative reason and an interest of practical reason and opposes these two to each other. From the perspective of Kant's philosophy this is correct, but it is not correct in itself; for reason is always one and has only one interest. The interest of reason lies in confidence in one's own self-sufficiency and freedom, and reason's interest in unity and coherence is a consequence of this prior interest. One could call the latter "the interest of speculative reason".... (FTP, 95; GA IV $/ 3,335$ )

consist in reason's having induced an optimal organization of all well-founded cognitions, via the implementation of certain self-legislated directives and the accordant articulation of an array of organizing non-sensory notions. The sort of optimal organization aimed at here is perfect systematicity, such that all given phenomena are rendered fully and finally intelligible in the most comprehensive and illuminating way. The self-legislated directives implemented to that end are the regulative principles of reason's theoretical employment: "to find the unconditioned for conditioned cognitions of the understanding" (A307/B364), and so forth. And the organizing non-sensory notions articulated on that basis include the key Ideas of reason - God, the world-whole, and the soul - as regulative representations: orienting projections (not warranted cognitions) of transcendent beings the (uncertain) existence of which would make possible the world's optimal intelligibility.

Next, regarding practical reason, we might say: Optimized autonomy would involve reason's having induced an optimal coordination of all particular volitions, via the implementation of certain self-legislated directives and the accordant articulation of an array of organizing non-sensory notions. The sort of optimal organization aimed at here is a systematic maximization of rational self-determination, such that all rational beings act out of unconditional respect for autonomy as such and, as a result, enjoy as much success in free self-actualization as is possible consistent with the same for all others. The self-legislated directives implemented to that end are the various versions of the categorical imperative. And the organizing non-sensory notions articulated on that basis include the key Ideas of reason - God, the world-whole, and the soul - as 
practical postulates: transcendent beings whose existence we can rationally affirm because, although our evidence is and must be silent on that question, such beings must exist if it is to be genuinely possible for us to achieve the in-principle optimum of autonomy to which reason as such unconditionally commits us.

Understood along something like the above lines, Kant's separate accounts of theoretical and practical reason seem to point toward the existence of a single, ultimate form of rational activity that has a single highest goal. ${ }^{x i i}$ In both the theoretical and the practical spheres, reason gives the rational being the end of inducing an optimal ordering, according to standards of optimality that reason itself authors a priori, and via the application of more specific ordering principles that reason itself articulates. In both spheres, then, reason is as the origination and application of pure ordering forms, chief among them a self-legislated supreme end of complete (optimal, unqualified, absolute) rational ordering. This end would be the transcendentally purest and normatively highest of reason's self-wrought ordering forms, such that "the goal of our entire existence and all of our acting ... [is] that rational being become absolutely and entirely free, self-sufficient, and independent of everything that is not itself reason" (AD, 101; GA I/5, 426). Rational activity in its absolutely pure form ought, in the end, to be all in all - the final goal, on the path toward which the I as an Idea (per the analysis in section 2) represents the penultimate step.

But then what accounts for reason's seeming differentiation into distinctly theoretical and practical forms? Kant's diffraction model, imported into this context, supports a straightforward answer: Reason's originally undifferentiated ultimate commitment (to absolute, unqualified, optimal ordering via pure, self-wrought forms) is, at its interface with the empirical, confronted and qualified by rationally-unbidden givens of two distinct kinds, the concrete qualitative character of which is, in each case (and from the standpoint of transcendental philosophy) absolutely contingent. Some of these arational factors are such that their opacity and recalcitrance vis-à-vis the selftransparency and spontaneity of rational activity confront the active intelligence with a mass of given facts. By contrast, some unbidden givens are such as to subject the rational being's pure power of self-determination to a kind of pressure or prompting not authored by that power itself: adventitious inclination. On this model, then, rational activity takes on a specifically theoretical or ethical cast (categorial articulation or normative evaluation) only in relation to the specific sort of occlusion or interference that contingently comes between reason and its self-legislated supreme end of absolutely unrestricted rational ordering. Thus it is a certain duality in the basic modes of arational manifestation that grounds reason's dual specialization in theoretical explanation and ethical orientation. "All of man's powers," on Fichte's account, "in themselves constitute but one power and are distinguished from each other merely in their application to different objects" (EPW, 149; GA I/3, 30).

41 As we saw above, Kant's thinking appears to embody separate applications of the diffraction model to each of two foundationally-unintegrated ultimate goals of rational activity: on the theoretical side, perfected comprehension, and on the practical side, optimized autonomy. Each of these ends is then further subjected to a kind of triple specification, as a result of the threefold basic articulation of rational activity's unchosen environment, per Kant's conception thereof. On the theoretical side, the aspiration to complete comprehension finds itself faced with three distinct topics: the subject, the world of appearances, and things in general. And on the practical side, the 
aspiration to optimized autonomy confronts three key challenges: effacing inclination, escaping full prior causation, and ensuring an optimal final situation. Consequently, reason can clearly envision the demanded completion of its own basic tasks (and in that way help to guide us toward said completion) only by abstractly modeling the indicated range of object-domains a priori - that is, only by elaborating multiple Ideas that serve that very purpose. For Fichte, by contrast, reason engenders its ultimate Idea not so that we might (as in the Kantian case) better model an order of things within which we are pictured as already embedded, but instead, simply so as to sustain our constant (if only tacit) recognition that, as finite rational beings, we are continually called upon to increase reason's freedom and extend reason's reach. "Ideas," for Fichte, "are problems or tasks for thinking, and they occur in our consciousness only to the extent that we are able to comprehend at least this task" (SE, 67; GA I/5, 75).

In the light of this and similar passages, ${ }^{\text {xiii }}$ it appears that for Fichte, Ideas represent principles and possibilities that fundamentally condition but finally surpass the entire finite-rational frame of reference. As such, Ideas are rationally and/or philosophically indispensable, even though their objects are only vaguely comprehensible. In closing, then, a related remark on the topic of illusion, which is a major theme in Kant that has no distinct echo in Fichte. Fichte's silence on this score should not surprise us, given the content of reason's highest Idea on his own account. After all, the I as an Idea can fulfill its orienting function only insofar as it is, in a sense (and for each of us), an idea of me - that is, of who, or better yet how, I, as a rational being, am finally called upon to be. But this Idea simultaneously demands from me a 'me' that, through my own effortful endeavor, has been purified and perfected to such a degree as to appear impossibly remote from my current condition - and indeed from any foreseeable moment in a life like mine, given that I am constantly called upon to manage unbidden sensations and master arational motivations. Thus there is no question of my somehow mistaking my pure-rational orientation via the I-as-an-Idea for an exact extrasensory identification of anything that I could rationally regard as real. On the contrary: this Idea ordinarily fulfills its role precisely via its obscure but insistent indication that "my goal lies in infinity, because my dependence is infinite" (SE, 143; GA I/5, 141). ${ }^{\text {xiv }}$

\section{ENDNOTES}

i. . For further exploration of these issues, see Susan Neiman, The Unity of Reason (Oxford University Press, 1994), Ch. 2.

ii. . Translation modified in all quotations that cite SK.

iii. . In the System of Ethics Fichte also says the following:

Everyone becomes God, to the extent that one is permitted to do so - that is, so long as one preserves the freedom of all individuals. It is precisely by means of this disappearance and annihilation of one's entire individuality that everyone becomes a pure presentation of the moral law in the world of sense and thus becomes a 'pure I,' in the proper sense of the term. (SE, 245; GA I/5, 231) 
As the context makes clear, however, Fichte is speaking here of an approximation to divinity that is accomplished in every instance of intramundane moral agency. Insofar as one can 'become God' in that sense on any given day, such pseudo-apotheosis cannot be equated with the envisioned completion of the "fusion ... into the absolutely pure form of reason or into God" referenced above. The latter goal, Fichte holds, "necessarily lies in infinity; it is certainly not an end that can ever be achieved" (SE, 142; GA I/5, 141).

iv. . Elsewhere I argue that the Jena Wissenschaftslehre, on Fichte's own understanding of it, also provides good rational grounds (just not specifically epistemic grounds) for principled assent to the existence (not to say the "being') of "infinite reason" as ordo ordinans of a supersensible moral order or "world of reason" (VM, 94; GA I/6, 280). See Steven Hoeltzel, "Fichte, Transcendental Ontology, and the Ethics of Belief," in Transcendental Inquiry, ed. Halla Kim and Steven Hoeltzel (Palgrave Macmillan, 2016), 55-82. I address related issues and likely objections in "Transcendental Idealism and Theistic Commitment," in The Palgrave Handbook of German Idealism, edited by Matthew C. Altman (Palgrave Macmillan, 2014), 364-85, and in "Nonepistemic Justification and Practical Postulation in Fichte," in Fichte and Transcendental Philosophy, ed. Tom Rockmore and Daniel Breazeale (Palgrave Macmillan, 2014), 293-313.

v. . To that end, see especially Michelle Grier, Kant's Doctrine of Transcendental Illusion (Cambridge University Press, 2001).

vi. . Cf. Fichte at SE, 59; GA I/5, 68.

vii. . See R 5553, AK 18:226; cf. R 5642, AK 18:280-1.

viii. . For further development of this point, see Michael Rolhf, "Ideas of Pure Reason," in The Cambridge Companion to Kant's Critique of Pure Reason, ed. Paul Guyer (Cambridge University Press, 2010), 205-6. For helpful historical and conceptual context, see Paul Guyer, "The Unity of Reason: Pure Reason as Practical Reason in Kant's Early Conception of the Transcendental Dialectic," in Kant on Freedom, Law, and Happiness, (Cambridge University Press, 2000), 78-84.

ix. . For a defense of the interpretation behind this claim, see Paul Guyer, "The Possibility of the Categorical Imperative," in Kant on Freedom, Law, and Happiness, 172-206.

x. . Here I focus mostly on the discussion in the second Critique, not on the "Canon of pure reason" in the first. For a more detailed treatment, see Paul Guyer, "From a Practical Point of View: Kant's Conception of a Postulate of Pure Practical Reason," in Kant on Freedom, Law, and Happiness, 333-71.

xi. . To be sure, Fichte also countenances various additional, systematically less-significant Ideas. Because space is limited, I cannot survey these here, but see the summary remark in this essay's closing paragraph.

xii. . For a more detailed presentation and defense of this proposal, see Steven Hoeltzel, "The Unity of Reason in Kant and Fichte," in Kant, Fichte, and the Legacy of Transcendental Idealism, ed. Halla Kim and Steven Hoeltzel (Lexington, 2014), 129-52.

xiii. . See, for example, FTP, 200-1; GA IV/3, 392.

xiv. . Many thanks to my colleagues at the thirteenth biennial meeting of the North American Fichte Society for their valuable feedback on an earlier version of this essay.

\section{ABSTRACTS}

In this paper, I argue that Fichte's account of pure reason and its supreme self-wrought Idea is, in its transcendental essentials, very much modeled on Kant's. The key difference between their positions, I suggest, is simply that Fichte operates with a more abstract understanding of the transcendentally basic elements of finite rationality; consequently, he arrives at a conceptually more concentrated understanding of pure reason's preeminent Idea. In section one, I supply some context for that comparison. In section two, I recount Fichte's depiction of "the I as an 
Idea" and note some importantly related concepts and claims. In section three, I examine a pair of interestingly different approaches taken by Kant to understanding and identifying the Ideas engendered by reason's basic aims and operations. Finally, in section four, I suggest that the Jena Wissenschaftslehre reflects Fichte's tacit appropriation of the transcendentally more fundamental of those two Kantian approaches.

INDEX

Keywords: I, transcendental ideas, finitude of reason, Kant, Fichte

\section{AUTHOR}

STEVEN HOELTZEL

James Madison University 